\title{
DUPATTA STRANGULATION CAUSING TRACHEAL INJURY AND STENOSIS, A COMMON NORTH INDIAN SCENARIO: A CASE REPORT
}

\author{
Authors: Shahab Ali Usmani (1) Kinjal Shankar Majumdar (2) P. Achyuth (3) S.P. Agarwal (4)
}

Authors Affiliation: $(1,2,3)$ Senior Resident, (4) Professor, Department of Surgical Oncology AllMS, Rishikesh

\section{ABSTRACT:}

Closed tracheal injuries are rare but are more frequent in northern India. Ladies wear Dupatta (A Scarf) around the neck which causes strangulation injury when entangled in the rear wheel of motorcycle or rickshaw. Because of rarity of such cases, it is often difficult for physicians at periphery to diagnose it early adding to the morbidity. We report a12-years old girl who presented to us with severe stridor and grade III tracheal Stenosis following dupatta strangulation while she was riding motorcycle. She was previously treated with T-tube placement in the trachea for 6 months, which was removed a week back. The patient underwent urgent tracheostomy followed by CECT which showed $2 \mathrm{~cm}$ grade III tracheal tenosis below the cricoid cartilage. The patient underwent tracheal resection and anastomosis. The patient recovered well, without any change in voice and restenosis on bronchoscopy in 5 months follow-up.

\section{Key Words:}

\section{INTRODUCTION}

Tracheal injury due to strangulation with dupatta while riding motorcycle is uncommon in other parts of the world but is a common mechanism of injury in northern India where females use dupatta (a long scarf). The females mostly sit with both the legs on one side and dupatta getting stuck in the spokes of rear wheel of the bikes leading to fall and strangulation injury. The Cricotracheal separation of the upper airway following neck trauma is a rarity [1-3].The rarity of this type of injury often leads to a delay in diagnosis which may contribute to airway patency problems, vocal production, and swallowing [4].Presenting symptoms can be nonspecific and a high index of clinical suspicion may be required for early diagnosis and suitable management. We report a case where multiple surgeries were required for strangulation injury with dupatta leading to tracheal disruption and grade III stenosis leading to severe morbidity.

Keywords: tracheal stenosis, strangulation, tracheal injury

\section{CASE PRESENTATION:}

A 12-years-old female was referred to AllMS Rishikesh (A tertiary care center) with complaints of severe respiratory distress. She had a history road traffic accident 6 months ago, while riding on motorcycle and her dupatta got caught into the rear wheel of the motorcycle strangulating her neck. She immediately had respiratory distress and was rushed to a local hospital in her village. She was treated there for a week for local abrasions on neck and respiratory distress and when the condition did not improve, she referred to another center in the city. There she was evaluated, and urgent tracheostomy was done. The neck soft tissue injuries along with the tracheal injury and disjunction were reported. After stabilizing the patient, a Montgomery T-tube was put at the tracheostomy site, bridging the superior and the 
inferior segments. The T- tube was removed after 6 months. She was discharged after 2 days of observation in hospital in stable condition. After 2 weeks she again developed respiratory distress for which she was referred to higher center.

On examination in OPD at AlIMS, Rishikesh, she was having stridor at rest which was increasing on lying down. She was using accessory muscles of respiration, otherwise she was conscious oriented, and her vitals were stable. We immediately did air tracheogram [ figure 1] which showed significant stenosis of the tracheal segment below the cricoid cartilage. We did a urgent tracheostomy in view of respiratory distress. Tracheostomy was done through the stenosed segment to preserve the normal trachea. Post tracheostomy after stabilizing the patient we did a contrast enhanced CECT scan which showed grade 3 tracheal stenosis below the level of the cricoid cartilage of $2 \mathrm{~cm}$ in length and diameter of about $4 \mathrm{~mm}$. The lumen was obliterated and fibrotic [figure 2].

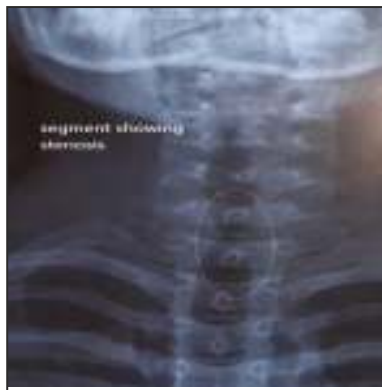

Figure 1

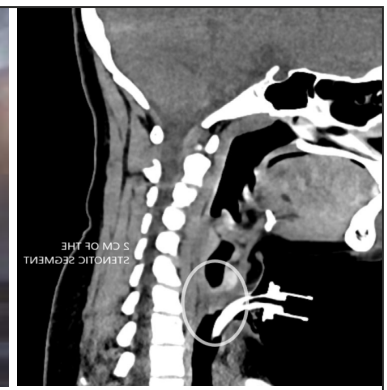

Figure 2
After stabilizing the patient and obtaining all routine investigations, we planned for resection of the stenosed segment and anastomosis.

The patient was anesthetized through the tracheostomy tube which was later changed to endotracheal tube. Laryngoscopy was done which showed a grade III trachea stenosis [figure 3]. On exposure of the trachea through the horizontal neck incision. The thyroid isthmus was cut in the midline and lobes were retracted laterally. We found $2.5 \mathrm{~cm}$ of the stenosed [figure 4].

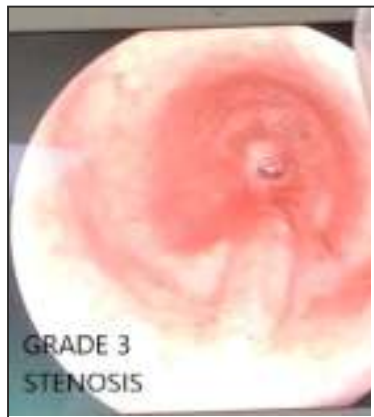

Figure -3

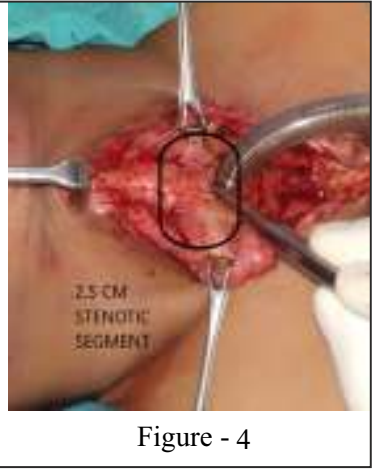

Figure -4
We excised the stenosed tracheal segment layer by layer to get normal segment without fibrosis. After resection, the segment was around $3.0 \mathrm{~cm}$ [figure 5] which was anastomosed primarily without tension with 4-0 PDS sutures using parachuting technique [figure 6].

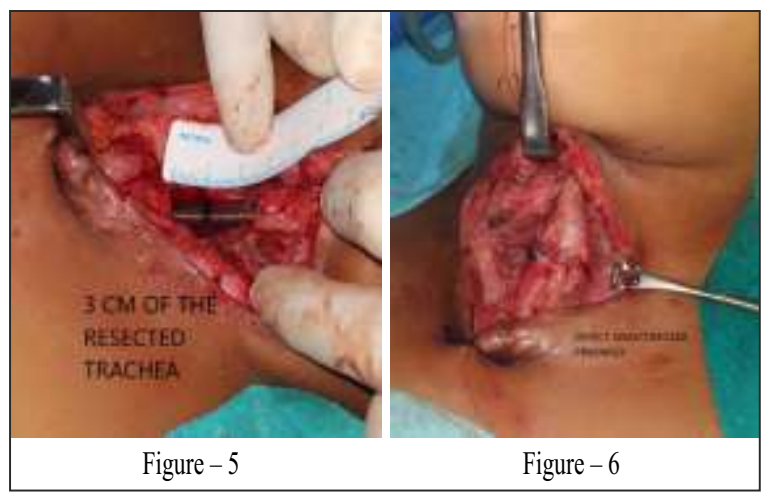

The knots of the anastomotic sutures lie outside of the trachea with $5 \mathrm{~mm}$ distance between each knot. The anastomosis is reinforced with thyroid gland and the strap muscles sutured over the trachea. A grillo suture from mandible to sternum was later applied to prevent extension of neck during post-operative period. The patient was kept in ICU with endotracheal tube, which was removed on post -operative day 1 . Post-operative day 2, laryngoscopy was performed to look for the status of the vocal cord and anastomotic segment. In which the vocal cords appeared mobile and anostosis was stable. The patient was observed in the ward for 3 days before discharge.Post-operative air tracheogram done on 4th post-operative day 


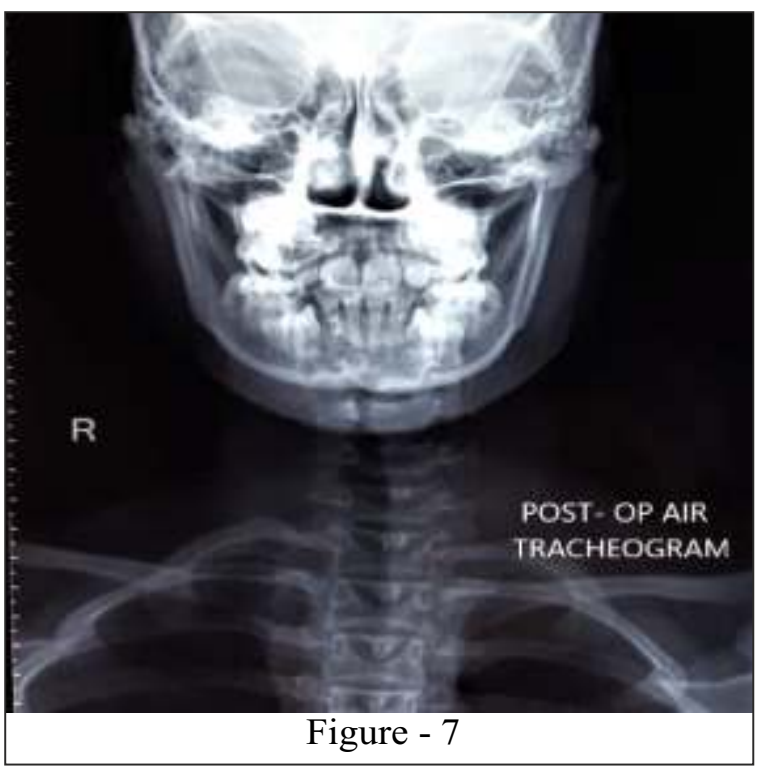

showed normal tracheal lumen [figure 7]. Patient is doing fine on follow up without any major issues 5 months post operatively.

\section{DISCUSSION:}

Closed tracheal injuries are rare but when associated with strangulation should be seen with strong suspicion of airway compromise. The most common symptom of laryngotracheal trauma is hoarseness. Other presenting symptoms can include dysphagia, pain, dyspnea, hemoptysis, and symptoms of airway obstruction such as stridor and tachypnea. Other signs include drooling and cervical subcutaneous emphysema and crepitation [5]. Strangulation injuries can also be associated with tracheal, laryngeal, esophageal injuries. There is a paucity of literature on management of such rare cases. In our case the patient was lucky to have survived both the accidental strangulation and the secondary stenosis. As she came to our hospital with grade III stenosis and just a pin hole opening left in the trachea. Moreover, she did not had any other esophageal, cervical and vascular injuries.

It was only in 1990 that Grillo demonstrated the feasibility of surgical treatment of tracheal stenosis for the first time and later, surgery for any type of tracheal disease requiring resection, including tumors, by resection of a portion of the trachea and its reconstruction by primary anastomosis [6,7].Resection and anastomosis are accepted as the treatment of choice for isolated tracheal stenosis [8]When the glottis is intact, segmental resection with cricotracheal or thyrotracheal anastomosis as a single stage procedure is found to be successful [9]. In our case as the stenosis was dense and $3.5 \mathrm{~cm}$ of the trachea was resected and anastomosed primarily without any tension. In 5 months of follow up there is patient did not have any anastomostic complication apart from local infection which was managed conservatively.

As these injuries are common in our part of the world, there should be public awareness for taking precautions while riding motorcycle and wearing Indian dresses with dupatta and sari. Any case of such strangulation injury should be evaluated for possible airway compromise. Early management and long term follow up should be initiated to reduce morbidity. Tracheal resection although challenging but has good long-term outcome.

\section{REFERENCES:}

[1] Chen F. H. and J. D. Fetzer, "Complete cricotracheal separation and third cervical spinal cord transection following blunt neck trauma: a case report ofone survivor," Journal ofTrauma, vol. 35, no. 1, pp. 140-142, 1993.

[2] Lee WT, Eliashar R, Eliachar I. Acute external laryngotracheal trauma: diagnosis and management. Ear Nose Throat J. 2006;85(3):179-184..

[3] Schaefer, S. D., The acute management of external laryngeal trauma: a 27-year experience. Archives of Otolaryngology, Head and Neck Surgery 118:598-604.

[4] Narci A., D.B.Embleton, A. Ayc, ic ek, F. 
Y"uceda"g, and S. C, etinkurs, un, "Laryngeal fracture due to blunt trauma presenting with pneumothorax and pneumomediastinum," ORL,vol. 73,no. 5, pp.246-248,2011.

[5]Juutilainen M, Vintturi J, Robinson S, Bäck L, Lehtonen $\mathrm{H}$, Mäkitie AA. Laryngeal fractures: Clinical findings and considerations on suboptimal outcome. ActaOtolaryngol 2008;128:213-8. [6] Grillo HC, Mathisen DJ, Wain JC. Management of tumors of the trachea.Oncology (Williston Park). 1992;6:61-7. discussion 68,70,72

[7] Grillo HC, Mathisen DJ. Primary tracheal tumors: treatment and results. Ann Thorac Surg. 1990;49:69-77.

[8]Grillo HC, The management of tracheal stenosis following assisted respiration, J. Thorac. Cardiovasc. Surg. 57 (1969) 52-71

[9] F.G. Pearson, L. Brito-Filomeno, J.D. Cooper, Experience with partial cricoid resection and thyrotracheal anastomosis, Ann. Otol. Rhinol. Laryngol.91 (1986) 322-328.

\section{Corresponding Author:}

Dr. Shahab Ali Usmani, MS (ENT), DNB, MRCS

Senior Resident, Department of Surgical Oncology,

AlIMS, Rishikesh

usmanishahab@hotmail.com 